\title{
The 2018-2020 Ebola Outbreak in the Democratic Republic of Congo: A Better Response Had Been Achieved Through Inter-State Coordination in Africa
}

\author{
Raoul Emeric Guetiya \\ Wadoum (iD) \\ Stephen Sevalie ${ }^{2}$ \\ Antonella Minutolo ${ }^{3}$ \\ Andrew Clarke ${ }^{4,5}$ \\ Gianluca Russo ${ }^{6}{ }^{6}$ \\ Vittorio Colizzi ${ }^{7}$ \\ Maurizio Mattei ${ }^{8}$ \\ Carla Montesano ${ }^{8}$
}

'Department of Public Health, Microbiology and Immunology, Ernest Bai Koroma University of Science and Technology, Makeni, Sierra Leone; ${ }^{2} 34$ th Regimental Military Hospital, The Republic of Sierra Leone Armed Forces, Freetown, Sierra Leone; ${ }^{3}$ Department of Experimental Medicine, University of Rome Tor Vergata, Rome, Italy; ${ }^{4}$ Global Programs Division, Save the Children United Kingdom, London, UK; ${ }^{5}$ Division of Health Research, Lancaster University, Lancaster, UK; ${ }^{6}$ Department of Public Health and Infectious Diseases, Sapienza University of Rome, Rome, Italy; ${ }^{7}$ Department of Biomedical Sciences, Faculty of Science and Technology, Evangelical University of Cameroon, Bandjoun, Cameroon; ${ }^{8}$ Department of Biology, School of Mathematics, Physics and Natural Sciences, University of Rome Tor Vergata, Rome, Italy
Correspondence: Raoul Emeric Guetiya Wadoum

Tel +232 78425924

Email ergwadoum@ebkustsl.edu.sl; raoulemeric@gmail.com

\begin{abstract}
The Ebola virus disease, formerly known as Ebola hemorrhagic fever, is a severe and often fatal zoonosis in humans. The 2013-2016 West African Ebola outbreak had distinctive characteristics, and it was the largest and most complex epidemic since the virus discovery in 1976. Although the 2018-2020 Ebola outbreak in the Democratic Republic of the Congo had many similarities, there were additional challenges due to the presence of armed rebel groups at the epicenters of the epidemic. Despite these challenges, the extraordinary commitment of the World Health Organization (WHO) regional office for Africa, in collaboration with Africa Union (AU) member states through the Africa Centres for Disease Control and Prevention (Africa CDC), and WHO's prompt declaration of a Public Health Emergency of International Concern (PHEIC) shepherded an effective coordinated response to contain the epidemic. Learning from previous Ebola virus epidemics and the current Coronavirus disease 2019 (COVID-19) pandemic, the AU member states should strengthen inter-state coordination towards the development and implementation of a preparedness and readiness plan which will enable the continent to build and sustain resilient capacities to prevent, detect, and respond to future outbreaks following the International Health Regulations (IHR).
\end{abstract}

Keywords: United Nations, Africa Union, WHO, Africa CDC, Ebola virus disease, COVID-19

\section{DR Congo Health Profile, System, and Infrastructure}

DR Congo is the largest second country on the African continent, with a population of over 70 million (Nigeria is the largest) and is the hub of Africa's most crucial continental crossroad, being bordered by Rwanda, Uganda, Burundi and Tanzania to the east, Central African Republic and South Sudan to the north, Angola and Zambia to the south, and the Republic of the Congo in the west. Formally established as a Belgian colony in 1908, DR Congo became independent in 1960, became Zaire in 1972, and became the Democratic Republic of the Congo in 1997. DR Congo has more than 200 ethnic groups and different languages, including French, Lingala, Kingwana, Kikongo, and Chilva as National languages. ${ }^{1}$

The conflict in DRC has resulted in a health-system collapse and created a humanitarian disaster. ${ }^{2}$ An estimated 5.4 million excess deaths occurred from 1997 to 2004 , with fewer than $10 \%$ attributable to violence and the rest to preventable and treatable medical conditions such as malaria, diarrhoea, pneumonia and malnutrition. ${ }^{3}$ In eastern Congo, the prevalence of rape and other sexual violence is documented as among the highest in the world. ${ }^{4}$ 
The country public health system is based on a fourtiered pyramid model. The first level consists of a community health centre where nurses provide primary care. The second level is a referral centre with resident doctors. The third level includes local hospitals that provide professional care and a university hospital representing the fourth level. The government works with many NonGovernmental Organizations to oversee the public health sector alongside the private sector.

\section{Ebola in DR Congo and WHO PHEIC Declaration}

In 2018, the DR Congo declared the second-largest Ebola virus disease (EVD) outbreak in history since the virus was first discovered in 1976. As of June 25, 2020, 3470 EVD cases had been reported, including 3317 confirmed and 153 probable cases, with 2287 death (overall case fatality ratio 66\%). Of the total confirmed and probable cases, $57 \%(\mathrm{n}=1970)$ were female, $29 \%(n=1002)$ were children under the age of 18 , and $5 \%(\mathrm{n}=171)$ were healthcare workers. With 1171 EVD survivors, the number of cases surpassed 3400, making it by far the country's largest-ever Ebola epidemic. ${ }^{5}$ Unlike previous outbreaks in the DRC, security challenges in North Kivu and Ituri Provinces hampered response efforts, making it difficult to identify and follow-up contacts of people infected with Ebola. As a result, the number of new cases doubled, from 1000 in March to around 2000 in June 2019. Despite the efforts of the DRC government, the World Health Organization (WHO), and partners, the number of new cases reported each week remained high, with a new case confirmed on 14th July in Goma, the capital of North Kivu and a city of one million people. In response to the discovery of this first case in Goma, WHO declared the Ebola epidemic in DR Congo to be a PHEIC on July 17, 2019. WHO Director-General promulgates this declaration following procedure set out in Article 49 of the International Health Regulations (IHR) after consulting the Emergency Committee (EC) established under Article 48 of IHR. When PHEIC is issued, WHO helps coordinate an immediate response with the affected country and any other state parties around the world. ${ }^{6}$

We described here the contextual framework of the international response to the 10th Ebola virus outbreak in DR Congo while revealing the nature of the leading national, regional and international agencies involved, including the United Nations (UN), WHO, African Union (AU) and the African centres for disease control and prevention (Africa $\mathrm{CDC}$ ) with a quick reminder on the foundations of the AU and Africa $\mathrm{CDC}$, and emphasizing on their mission to coordinate the response of $\mathrm{AU}$ member states towards public health emergencies on the continent. We concluded by showing how vaccines remain one of humanity's best weapons during public health emergencies.

\section{Potential Spillover to Nine Neighbouring States - Fear for an Unprecedented Major Humanitarian Crisis}

The possibility of the Ebola virus spilling over to neighbouring countries was factual, as evidenced by the reported case in Uganda confirmed in June 2019. Uganda was far more familiar with the Ebola virus as the country was struck with three outbreaks in 2000, 2007 and 2012, respectively. These epidemics have prompted the country to build capacity to respond to subsequent events, as shown by the rapid mobilization and deployment of a rapid response team tasked to identify others at risk. The scenario of Ebola spreading to the nine countries sharing borders with DRC was factual and scary as the life of about 290 million African citizens - representing 23\% of Africa's total population - was at risk (Table 1). In the eventuality that this spread happened, it would have led to an unprecedented major humanitarian crisis with a critical socioeconomic impact on Africa. For instance, the real gross national product growth of Sierra Leone, Liberia, and Guinea was expected to increase in 2014 and 2015 due to relatively high stock prices, rising domestic demand, and improved economic management and governance; however, this predicted economic growth was not realized due to the epidemic-related economic shrinkage. The high traffic at the DRC borders and insecurity constituted some drivers of spillover (Figure 1). However, organizations such as the European Union, United States Centers for Disease Control and Prevention (US CDC), and WHO supported countries sharing borders with DRC with initial provision to Uganda, South Sudan, Rwanda, and Burundi. ${ }^{8}$ These funds contributed to strengthening these countries' readiness in line with the WHO African region strategic Ebola preparedness plan (Figure 2).

\section{Outbreak Effort in DR Congo - Community Distrust and Insecurity Undermined Response}

Previous outbreaks of the Ebola virus had been sporadic, minor, and confined mainly in rural areas, but the West 
Table I Distribution of the Population in Countries Neighbouring the Democratic Republic of Congo

\begin{tabular}{|c|c|c|c|c|c|}
\hline Region & SDG $^{a}$ Region & Sub-Region & Country & Country Code & Population $^{\mathrm{b}}$ \\
\hline \multirow[t]{10}{*}{ Africa } & \multirow[t]{10}{*}{ Sub-Saharan Africa } & Middle Africa & The Democratic Republic of the Congo & 180 & 86,791 \\
\hline & & & Angola & 24 & 31,825 \\
\hline & & & Congo & 178 & 5381 \\
\hline & & & The Central African Republic & 140 & 4745 \\
\hline & & Eastern Africa & United Republic of Tanzania & 834 & 58,005 \\
\hline & & & Uganda & 800 & 44,270 \\
\hline & & & Zambia & 894 & $|7,86|$ \\
\hline & & & Rwanda & 646 & 12,627 \\
\hline & & & Burundi & 108 & 11,531 \\
\hline & & & South Sudan & 728 & 11,062 \\
\hline \multicolumn{5}{|c|}{ Total population at risk ( $\approx 23 \%)$} & 284,098 \\
\hline \multicolumn{5}{|c|}{ Total population of Africa } & 1308,064 \\
\hline
\end{tabular}

Notes: a SDG, Sustainable Development Goal; ${ }^{\text {T} T o t a l ~ p o p u l a t i o n, ~ b o t h ~ s e x e s ~ c o m b i n e d, ~ a s ~ o f ~ J u l y ~ I, ~} 202$ I (thousands); data from United Nations, Department of Economic and Social Affairs, Population Division. World population prospects 2019, Online edition; 2019. Available from: https://population.un.org/wpp/Download/Standard/ Population.$^{7}$

Africa epidemic opened a new venture, was multicountry, recorded cases above what has ever been recorded for Ebola, and killed more than 15,000 people. ${ }^{9}$ Subsequent outbreaks have been reaching densely populated urban areas, often resulting in an uncontrolled spread. Although the 10th Ebola epidemic in the Democratic Republic of the Congo involved 3470 confirmed and 153 probable cases, of which 2287 died (overall case fatality ratio $66 \%$ ) as of June 23, 2020, it was indeed smaller in magnitude, particularly in comparison to the West African epidemic, which involved more than 28,000 cases and 11,310 deaths (overall mean CFR 62.9\%). ${ }^{5,9}$ Unlike the West African outbreak, the DRC epidemic triggered a massive and intense international response, with the WHO declaring the emergency more quickly than ever before. Responding to the call of the DRC government, the rapid mobilization of the international community should have sufficed to contain the outbreak as seen in West Africa; however, violence and general insecurity in the DRC was a significant concern as the epicentres of the epidemic were located in provinces hosting multiple armed rebel groups. These security issues undermined efforts to contain the epidemic, as several incursions of armed groups in various sites were recorded, culminating in attacks that partially destroyed Ebola treatment units (ETU) in Butembo, Katwa and later in Beni. Violent attacks against the Ebola response, coupled with mistrust, continued to hamper the efforts to control the outbreak and further traumatized the population; thus, preventing them from seeking care in ETU.

\section{The Necessity for Inter-State Coordination in Africa}

The World Health Organization and international agencies commemorated the 100th anniversary of the Spanish Flu pandemic in 2018, which infected 500 million people worldwide and killed over 100 million people, making it one of the deadliest natural disasters in the history. ${ }^{10}$ Until the current Coronavirus disease 2019 (COVID-19) pandemic, the world had not seen a public health emergency of that magnitude. However, the 2014 Ebola outbreak in the Mano River region taught us that such epidemics are sporadic and that the world remains particularly susceptible because we do not know when or where the next global public health disaster will occur. The situation in the DRC was alarming and could have become a significant concern, with approximately $23 \%$ of Africa's total population at risk of a major humanitarian disaster if interstate cooperation to contain the epidemic was not reinforced. Fortunately, the United Nations (UN) bill of rights, signed on June 26, 1945, in San Francisco and entered into force on October 24, 1945, paved the way for such cooperation. The United Nations is an intergovernmental organization tasked with preserving peace and stability and fostering global partnerships for development. The above mission is carried out by UN relevant agencies such as the Food and Agriculture Organization of the United Nations (FAO), the United Nations Educational, Scientific, and Cultural Organization (UNESCO), and the World Health Organization (WHO) among many others. ${ }^{11}$ 


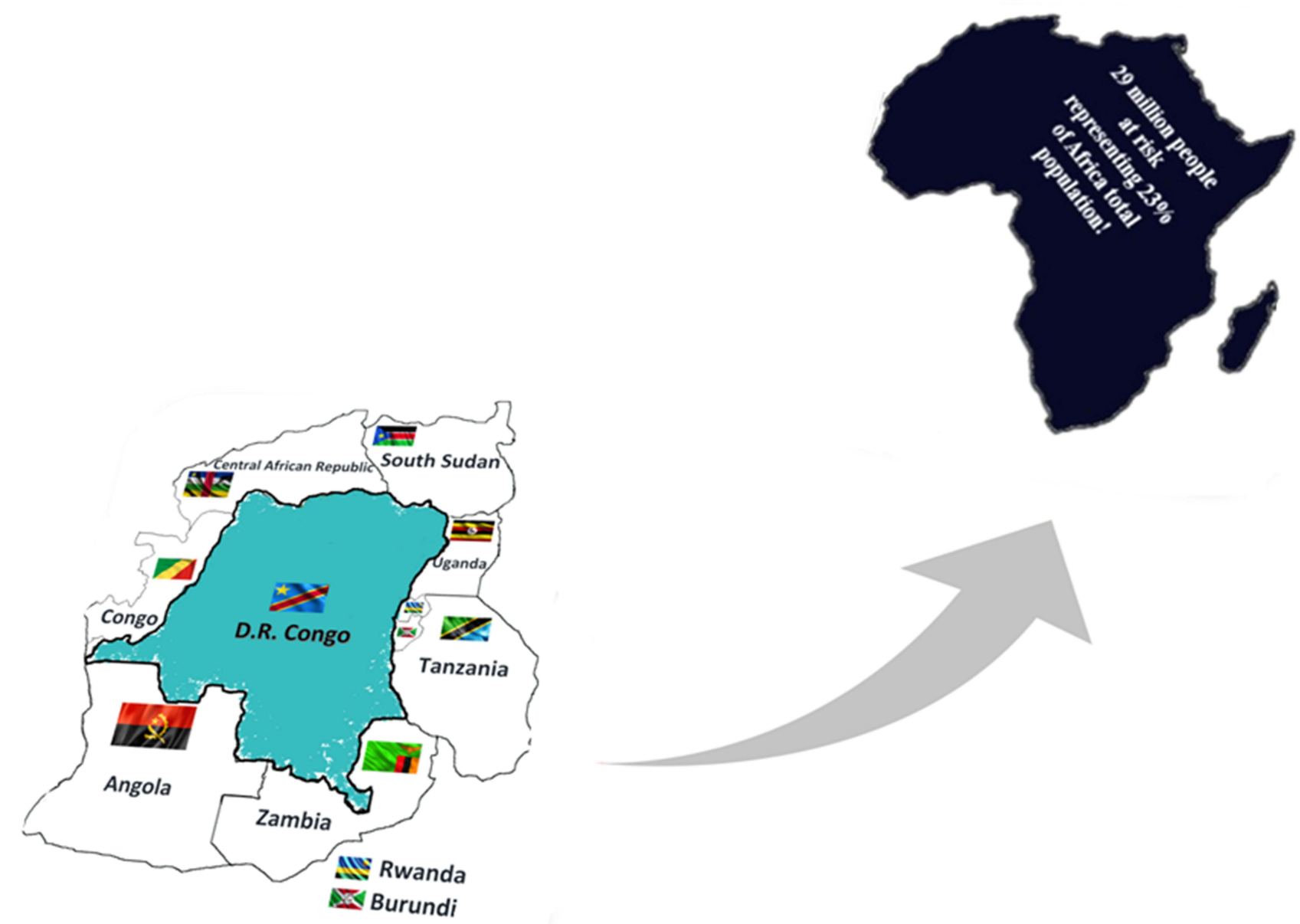

Figure I Democratic Republic of Congo and neighbouring countries at risk.

The African leaders expressed their willingness and devotion to play a more prominent role in and take complete responsibility for promoting African solidarity, unity, cohesion, and collaboration by establishing the Africa Union, a Pan-African institution (AU). The Organization of African Unity (OAU) was established in 1963 by agreement of 32 African states that had gained independence. A further 21 members gradually joined, bringing the total to 53 by the time the AU was established in 2002, with South Sudan becoming the 54th AU member in 2011. The AU's constitutive act recognized the need for member states to address the negative consequence of diseases by effectively implementing policy decisions to reduce the burden and improve public health in Africa. ${ }^{12}$ Concerned about Africa's rising disease burden, the AU developed the Africa Health Strategy (AHS) 2016-2030 to serve as a technical guide to ensure that member countries develop and sustainably improve their health sectors to ensure adequate monitoring and quality response to emergencies and disease epidemics on the continent. ${ }^{13}$
While the Peace and Security Council and the AU Executive Committee's establishment of African Union Support to the Ebola Outbreak in West Africa (ASEOWA) was a welcome development, the Ebola epidemic in the Mano River region was a humanitarian disaster of epic proportions that caught the entire global health world unprepared. It was no coincidence that initiatives such as the Coalition for Epidemic Preparedness Innovations (CEPI), Africa Centres for Disease Control and Prevention (Africa CDC), and the WHO R\&D blueprint unit were established after the outbreak. The 2014 outbreak was a failure of interstate coordination and not an example to be set as a standard.

Based on the success of ASEOWA, the Africa CDC was established as a specialized agency to assist AU member countries in their efforts to improve the health of their citizens by strengthening health systems through infrastructure development, epidemiological surveillance, and disaster response. ${ }^{14,15}$ 


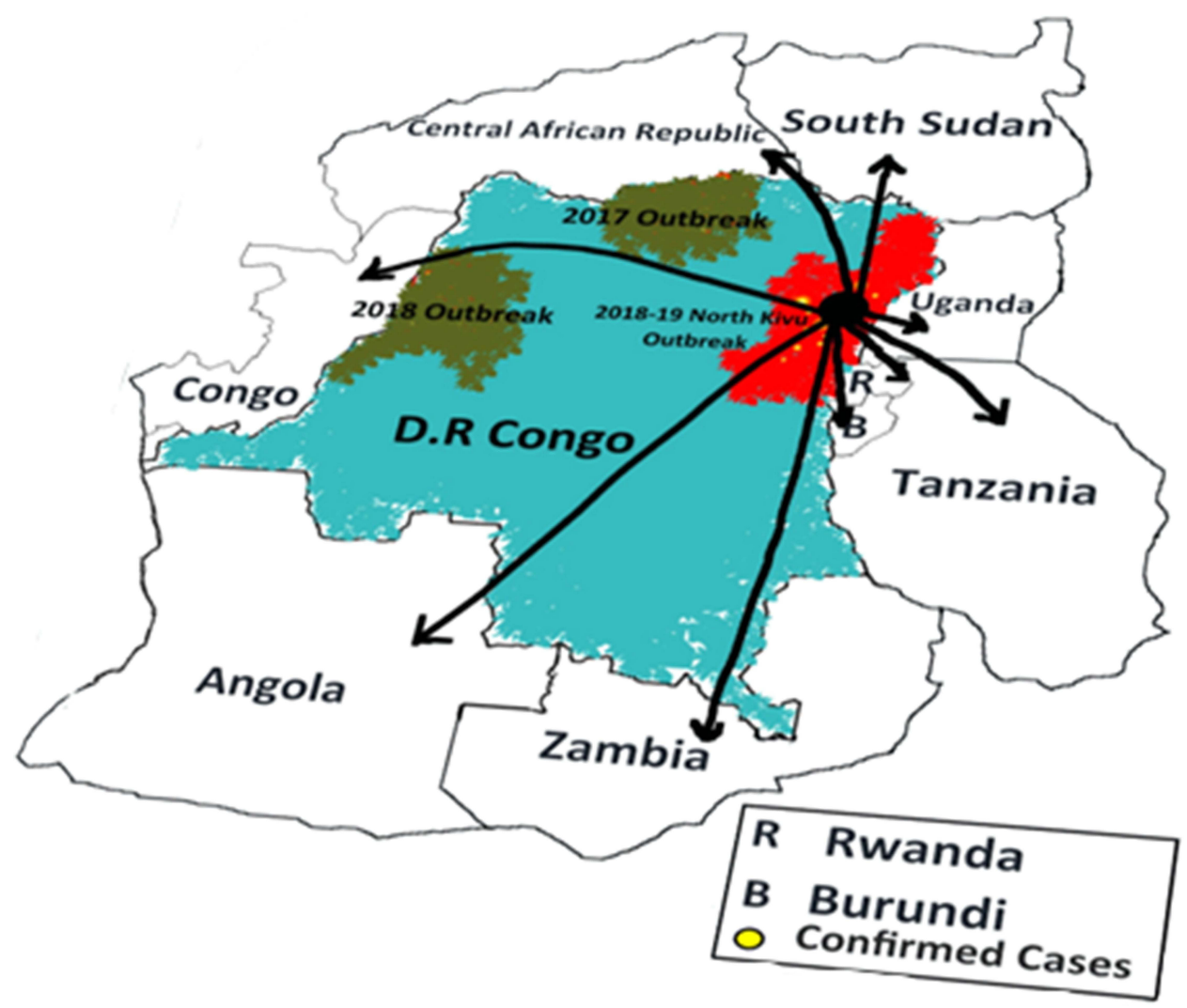

Figure 2 Potential spillover to nine countries sharing borders with the Democratic Republic of Congo.

\section{The Africa Centres for Disease Control and Prevention}

The Africa CDC is a technical institution of the AU tasked

\begin{abstract}
to support African countries to improve the health of the people by reducing the disease burden - especially infectious diseases - through prevention and treatment, surveillance and response to emergencies (including outbreaks, man-made and natural disasters, and public health events of regional and international concern), and capacitybuilding. ${ }^{16}$
\end{abstract}

On August 1, 2018, Africa CDC activated the Emergency Operations Centre (EOC) to coordinate the Ebola response, and it remains activated until the outbreak was declared over.

\section{The Action of Africa CDC in DR Congo} Africa CDC supported the DR Congo response efforts since the onset of the outbreak and had experts in the field, some of whom were members of the African Voluntary Health Corps (AVoHC) established in 2015 by the Heads of State of AU as a group of trained staff that can be mobilized and deployed as needed within the continent. In fulfilling its mandate, the Africa CDC recruited, trained and deployed an "Epidemic Response Team", which consisted of a multidisciplinary team of subject matter experts in areas of epidemiology, laboratory, logistics, communication, anthropology, environmental health, animal health and Incident Management System (Figure 3).

Epidemiologists from Africa CDC continued to attend the daily national coordination meeting in Kinshasa, where critical decisions were made with regards to the best way to contain the outbreak. Africa CDC field staff established good working relations with the Ministry of Health of the DR Congo and all the partners, including the WHO, Médecins Sans Frontiers (MSF), and others. In addition, staff were involved in diverse activities linked to the response as follows:

\section{Training}

More than 8000 local health care workers and community volunteers were trained by Africa CDC staff in disease surveillance, laboratory diagnostics, risk communication and infection prevention and control. 


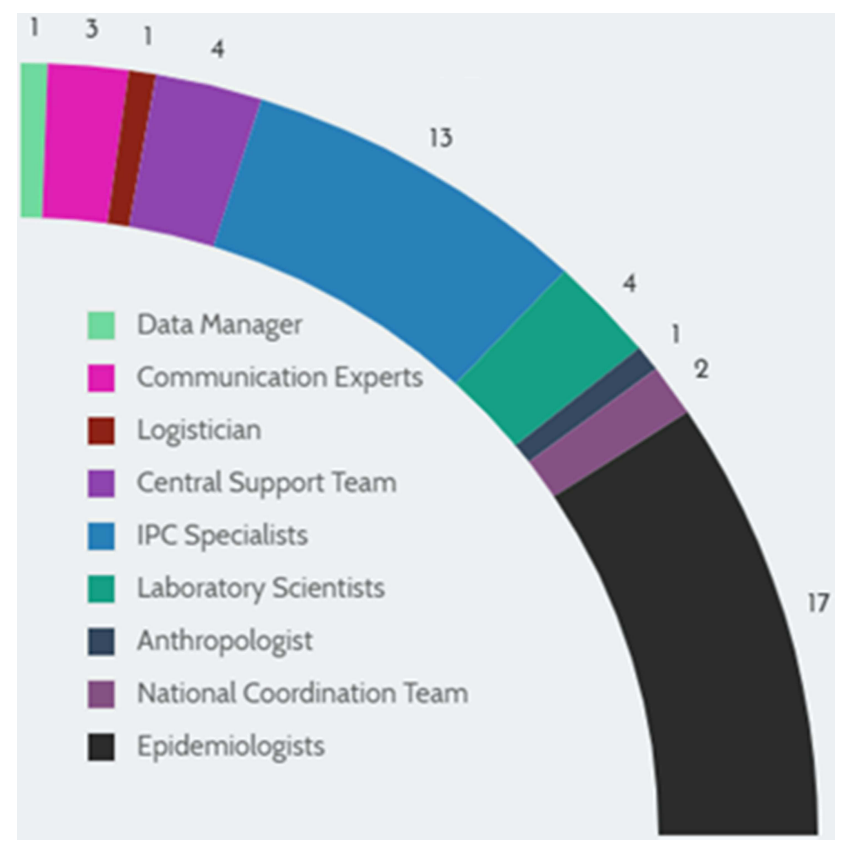

Figure 3 Africa CDC Ebola volunteers by expertise during the 2018-2020 Ebola outbreak Democratic Republic of Congo.

\section{Laboratory Services}

Africa CDC strengthened laboratory testing in affected health zones by procuring GeneXpert machines and cartridges to enable accurate real-time Ebola virus diagnostics and confirmation of suspected cases.

\section{Contact Tracing and Surveillance}

Africa CDC epidemiologists made significant contributions to surveillance and investigated potential clusters and sources of transmission. The surveillance activities comprised alert management, contact tracing of index cases jointly with health facility staff, and contact follow up.

\section{Infection Prevention and Control (IPC)}

Africa CDC IPC specialists conducted a situational analysis of hygiene in several health facilities, then designed and implemented training packages for health workers to enhance infection control. Moreover, handwashing facilities were provided to schools and public facilities.

\section{Cross-Border Surveillance}

In collaboration with other partners, more than 70 million people were screened at border crossings. Several volunteers were also trained on entry screening in partnership with the Ministry of Public health and WHO regional office for Africa.

\section{Vaccination}

Africa CDC team supported house-to-house visits in all affected health zones to enhance health education and mobilized contacts for vaccination. ${ }^{17}$

\section{Strategic Plan of Africa CDC Following the WHO PHEIC Declaration}

In response to the declaration by the WHO categorizing the 10th Ebola outbreak in DR Congo as a PHEIC, the Africa CDC director, in a briefing on July 192019 , confirmed that the AU re-activated the AVoHC and deployed teams in DR Congo and neighbouring countries. ${ }^{18}$ A few days later, on July 22, 2019, the Africa CDC and the WHO Regional Office for Africa reiterated the need for all AU Member States to adhere to the recommendations following the PHEIC declaration and confirmed that both would work closely to address the crisis in the DRC. ${ }^{19}$

Subsequently, AU's Peace and Security Council (PSC), at its meeting held July 2020, on the outbreak of Ebola in DRC, declared that

the outbreak of Ebola virus disease in the DRC is a source of grave concern, as well as a serious threat to peace and security in DRC, the region and the continent as a whole, and emphasizes the need for urgent measures to be taken to control the disease and eliminate it's spreading to other parts of the country or neighbouring countries. ${ }^{20}$

While the deployment of additional staff by Africa CDC was in preparation, the AU diplomatic and administrative leaders were on the frontline to facilitate the interstate mobilization of adequate resources to respond to the emergency. For example, a delegation from AU led by the commissioner of Social Affairs at the African Union Commission visited the DR Congo to evaluate the response, and the chairperson of the African Union Commission (AUC) subsequently convened a Forum for "Africa against Ebola Solidarity Trust Fund" (AAESTF) during the first week of September 2019 to mobilize funding to support the efforts in the DR Congo. ${ }^{21}$ These actions, taken together, underlined the dynamism and determination of AU member States to find a regional African solution to the epidemic. 


\section{Vaccine Perspectives in DR Congo During the I0th Ebola Outbreak: Fear vs Optimism Around Introducing a Second Experimental Vaccine}

Vaccines have fundamentally changed the way modern medicine is since their first inception in the 18th century, eliminating or decreasing the impact of some of the most fatal human diseases. Edward Jenner and Louis Pasteur laid the foundation of modern immunology and vaccinology, and their achievements continue to save lives and constitute the backbone of new vaccines discoveries.

Vaccines have efficiently been used to eradicate infectious diseases such as smallpox and control other infectious diseases such as Poliomyelitis, Yellow fever, diphtheria, and rabies. Despite these accomplishments, licensed vaccines against the Ebola virus were unavailable during the DRC's 10th Ebola outbreak. During the West Africa Ebola outbreak, a promising experimental vaccine containing a harmless vesicular stomatitis virus (VSV) engineered to carry a gene for a Zaire Ebolavirus surface protein was provided by Merck \& Co and tested following a "ring" vaccination strategy and proved to be highly effective and became the cornerstone of the effort to contain the epidemic in Guinea. The introduction of this highly efficacious vaccine in DR Congo in 2018 - initially introduced as an experimental vaccine and later received market authorization and $\mathrm{WHO}$ prequalification - helped contain the spread of Ebola by systematically vaccinating people at risk. Despite this achievement, the quantity of these lifesaving vaccines stocks was minimal, leading to fear that the vaccine could not be provided to all those at risk.

Given this challenge, the WHO advisory group recommended introducing a second experimental vaccine made by Johnson \& Johnson that required two shots: one of a nonreplicating adenovirus that includes an Ebola surface protein and then 8 weeks later, a modified inactive pox virus with several Ebola proteins.

The hope was that the combination of Merck \& Co and Johnson \& Johnson vaccines strategies enabled rapid control of the epidemic. However, the idea of the second vaccine in DR Congo was not welcomed positively by the DRC government to "not perturb the population", as stated by the then minister of health Oly Ilunga. Considering that the overall aim of all involved was to contain and stop the epidemic, the introduction of this second vaccine should not have raised fear but should have been welcomed with optimism. Even though the initial approach of the former DRC minister of health, Oly Ilunga, to stick to one vaccine was justifiable, it is now evident that introducing a second experimental vaccine was required. Moreover, both vaccines enabled the implementation of two immunization strategies, with the Merck \& Co vaccine providing immediate protection to close household contacts of index cases. In contrast, the Johnson \& Johnson vaccine effectively protected communities not immediately exposed or at risk.

\section{Conclusion}

The 10th Ebola outbreak in DR Congo was the second largest in the world and was particularly challenging given that the epicentres of the epidemic were in an active conflict zone controlled by armed rebel groups. However, the extraordinary commitment of the WHO regional office for Africa alongside AU's member States through the Africa CDC and the early declaration of the PHEIC by the WHO helped contain the epidemic. Moreover, vaccination proved once again to be an effective public health weapon to control outbreaks, as evidenced by the successful containment of the 2021 Ebola outbreak in Guinea.

Special consideration should be given to Ebola virus survivors, as it is now evident that the virus can persist in immune-privileged sites for more than 6 years, potentially leading to resurgence of new outbreak, like the 2021 Ebola outbreak in Guinea, with new findings linking the outbreak to a survivor of the major 2013-2016 West Africa Ebola outbreak. ${ }^{22}$ Finally, AU Member States should develop and implement a preparedness and readiness plan which will enable the continent to build and sustain resilient capacities to prevent, detect, and respond to the outbreak following the international health regulations.

\section{Disclosure}

The authors declare that they have no conflicts of interest for this work.

\section{References}

1. The constitution of the Democratic Republic of the Congo; 2015. Available from: http://www.constitutionnet.org/files/DRC\%20-\% 20Congo\%20Constitution.pdf. Accessed November 10, 2021.

2. Zarocostas J. Some 45,000 people die each month in Congo as a result of collapsed health service, says UN official. BMJ. 2009;338:b2652. doi:10.1136/bmj.b2652

3. Coghlan B, Brennan RJ, Ngoy P, et al. Mortality in the Democratic Republic of Congo: a nationwide survey. Lancet. 2006;367(9504):4451. doi:10.1016/S0140-6736(06)67923-3 
4. Brown C. Rape as a weapon of war in the Democratic Republic of the Congo. Torture. 2012;22(1):24-37.

5. World Health Organization. Ebola situation reports: the Democratic Republic of the Congo as of June 23, 2020. Available from: https:// apps.who.int/iris/bitstream/handle/10665/331815/SITREP_EVD_ DRC_20200421-eng.pdf. Accessed June 25, 2021.

6. World Health Assembly. International health regulations (2005). Geneva: World Health Organization; 2006. Available from: https:/www.who.int/ ihr/ports_airports/PoE_Core_capacity_assement_tool.pdf. Accessed June 252021.

7. United Nations, Department of Economic and Social Affairs, Population Division. World population prospects 2019, Online edition; 2019. Available from: https://population.un.org/wpp/Download/ Standard/Population/. Accessed June 25, 2021.

8. European Union; European Commission. Ebola: EU releases additional $€ 3.5$ million to tackle epidemic; 13 June 2019 [Press release]. Available from: https:/ec.europa.eu/commission/presscorner/detail/ en/ip_19_2990. Accessed December 4, 2021.

9. Centers for Disease Control and Prevention. 2014-2016 Ebola outbreak distribution in West Africa. Available from: https:/www.cdc.gov/vhf/ ebola/history/2014-2016-outbreak/distribution-map.html. Accessed June $25,2021$.

10. Centres for Disease Control and Prevention. The deadliest flu: the complete story of the discovery and reconstruction of the 1918 pandemic virus. Available from: https://www.cdc.gov/flu/pandemicresources/reconstruction-1918-virus.html. Accessed June 25, 2021.

11. United Nations. Charter of the United Nations. Available from: https://www.un.org/en/sections/un-charter/introductory-note/index. html. Accessed June 25, 2021.

12. Africa Union. Constitutive act of the African Union. Available from: http://www1.uneca.org/Portals/ngm/Documents/Conventions\%20and \%20Resolutions/constitution.pdf. Accessed June 25, 2021.

13. Africa Union. Africa health strategy 2016 - 2030. Available from: https://au.int/sites/default/files/pages/32895-file-africa_health_strat egy.pdf. Accessed June 25, 2021.

14. Africa Union. The stature of the Africa Centres for Diseases Control and Prevention (Africa CDC). Available from: https://au.int/sites/ default/files/documents/30730-doc-africa_centre_for_disease_con trol_validated_and_clean.pdf. Accessed June 25, 2021.
15. Nkengasong JN, Maiyegun O, Moeti M. Establishing the Africa Centres for Disease Control and Prevention: responding to Africa's health threats. Lancet Glob Health. 2017;5(3):246-247. doi:10.1016/ S2214-109X(17)30025-6

16. Africa Centres for Disease Control and Prevention. Africa CDC strategic plan 2017 - 2021. Available from: http://www.africacdc. org/press-centre/fact-sheets-and-brochures. Accessed June 25, 2021.

17. Africa Centres for Disease Control and Prevention. Africa CDC Twitter account. Available from: https://pbs.twimg.com/media/D_ 29y0MXsAArkMQ.jpg. Accessed July 21, 2020.

18. Africa Centres for Disease Control and Prevention. Press Release No 015/2019. African Union to deploy more experts in response to Ebola outbreak in the DRC. Available from: http://www.africacdc.org/presscentre/press-releases-pdf-version/press-releases/press-release-no-0152019-african-union-to-deploy-more-experts-in-response-to-ebola-out break-in-The-drc-en-pdf/download. Accessed July 22, 2020.

19. Africa Centres for Disease Control and Prevention. Press Release No 016/2019. Joint press release between Africa centres for Disease Control and Prevention and the World Health Organization on The situation of ebola virus disease outbreak in the Democratic Republic of Congo. Available from: https://au.int/en/pressreleases/20190722/ joint-press-release-between-africa-cdc-and-who-ebola-outbfreak-drc. Accessed July 22, 2020.

20. Africa Union. PSC/PR/COMM. (DCCCLXII). Communiqué of the 862nd meeting of the PSC, held on July 23, 2019, on the outbreak of Ebola in the Eastern part of the Democratic Republic of Congo (DRC). Available from: http://www.peaceau.org/uploads/psc-862comm-ebola-drc-23-07-2019.pdf. Accessed July 22, 2020.

21. Africa Union. Chairperson of the AU Commission to convene a forum of African private sector and donors to mobilize resources for Ebola response in DRC. Available from: https://au.int/sites/ default/files/pressreleases/37065-pr-press_release-_chairperson_of_ the_au_commission_to_convene_a_forum_of_african_private_sec tor_and_donors_to_mobilize_resources_for_ebola_response_in_drc. pdf. Accessed July 22, 2020.

22. Fairhead J, Leach M, Millimouno D. Spillover or endemic? Reconsidering the origins of Ebola virus disease outbreaks by revisiting local accounts in light of new evidence from Guinea. BMI Glob Health. 2021;6:5783-5784.
Risk Management and Healthcare Policy

\section{Publish your work in this journal}

Risk Management and Healthcare Policy is an international, peerreviewed, open access journal focusing on all aspects of public health, policy, and preventative measures to promote good health and improve morbidity and mortality in the population. The journal welcomes submitted papers covering original research, basic science, clinical \& epidemiological studies, reviews and evaluations,

\section{Dovepress}

guidelines, expert opinion and commentary, case reports and extended reports. The manuscript management system is completely online and includes a very quick and fair peer-review system, which is all easy to use. Visit http://www.dovepress.com/testimonials.php to read real quotes from published authors. 